\title{
成層混合気中の維持火炎に及ぼす火炎伸長の影響*
}

\author{
北川敏 明*1, 城戸裕之*1, 金 奎 成*2 \\ 中村 望*3, 相 嶋 匡也*3
}

\section{The Effects of Flame Stretch on Supported Flame in Stratified Mixture}

\author{
Toshiaki KITAGAWA*4, Hiroyuki KIDO, Kyu-Sung KIM, \\ Nozomu NAKAMURA and Masaya AISHIMA
}

${ }^{* 4}$ Department of Mechanical Engineering Science, Kyushu University,
6-10-1 Hakozaki, Higashi-ku, Fukuoka-shi, Fukuoka, 812-8581 Japan

\begin{abstract}
The flame propagating into the lean region of the stratified mixture below the lower flammability limit was supported by the burned gas behind it. In this study, the effects of the flame stretch on this supported flame was investigated numerically. The supported flame and the burned gas behind it were linked to the counterflow flame configuration of the lean mixture and the hot nitrogen. The results show that the flame stretch deteriorates the reaction of the supported flame. The production of $\mathrm{CO}$ and unburned hydrocarbons increases with increasing the flame stretch rate. Moreover, the self-sustaining flame in the flammable range turns into the supported flame by the intense stretch.
\end{abstract}

Key Words: Internal Combustion Engine, Fuel Injection, Flammability Limit, Stratified Charge, Supported Flame, Flame Stretch, Counterflow Flame

\section{1. まえがき}

火花点火機関において，筒内へ燃料を直接噴射する 成層給気方式は, 希薄燃焼を実現するための有効な手 段である(1ん(2)。この方式においては，火炎は燃料濃度 勾配を有する成層混合気中を伝播する，従って，この 方式の更なる改善には, この成層混合気中の火炎伝播 特性を明らかにすることが重要である.

様々なスケールで複雑に成層化された場においては, 過濃, 希薄領域の混在による triple flameや edge flame の出現(3) - (10)とそれら希薄および過濃火炎の相互作用

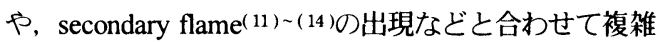
な燃焼場になっているものと考えられる.

著者らもこれまでに，成層混合気において火炎がど のように成層混合気中を伝播するのかを明らかにして きた(12)ー(16)，そのうち，前報では(15)，希薄領域への火

\footnotetext{
* 原稿受付 2003 年 9 月 22 日.

*1 正員, 九州大学大学院工学研究院 (严812-8581 福岡市東区 箱崎 6-10-1).

*2 正員, 九州大学大学院工学府.

*3 九州大学大学院工学府.

E mail : toshi « mech.kyushu u.ac.jp
}

炎伝播を調べるために，可燃限界以下の希薄予混合給 気中に気体燃料を噴射する実験を行った. その結果, 燃料噴流内で形成された火炎は, 希薄可燃限界以下の 濃度の領域にもある程度伝播した後，消炎することが 明らかとなった．また，希薄混合気の濃度が高いほど, 火炎が伝播する希薄混合気の領域は, 広いことが明ら かとなった.

燃料濃度の高い領域で形成された火炎は, 可燃限界 以下の希薄領域に達した後も, 火炎背後からの熱およ びラジカル等の拡散などによる火炎維持(back-support) 効果 17 ( 18 )を受けて，ある期間伝播するものと考えら れる. そして，その火炎の慣性(flame inertia)(17)が，伝 播中の希薄混合気の濃度が高いほど減衰しにくいため に, 火炎背後から維持された火炎(supported flame)(17) は長期間維持され伝播し続けるものと考えられる.こ こでは, このような火炎を, 維持火炎と呼ぶ(16).

成層混合気中の火炎の特性については，対向流予混 合火炎を用いた研究(15) 〜 (17)(19)(20)がなされている. 著 者らは前報(15)，(16)において，可燃混合気中に形成され た火炎(self-sustaining flame)(21)の希薄領域への伝播を, 濃度勾配の方向に伝播する火炎およびその背後の燃焼 
ガスと前方にある希薄混合気の相互作用としてとらえ， 希薄混合気と高温窒素, 燃焼ガスあるいは可燃範囲内 にある当量比の混合気を対向させる数値計算を行った. そして, 燃料の反応速度など, この維持火炎の特性に ついて検討を行った.

一方, 予混合火炎および拡散火炎とも, 燃焼速度, 着火, 消炎など, 火炎には火炎伸長が大きな影響を及 ぼすため, 多くの研究がなさており(4) (6)(22) (25), 維持 火炎についてもその影響があるものと考えられる.ま た, 乱流火炎においては, 乱机による火炎伸長の影響 は重要である(26)，そして, 対向流火炎は, これら火炎 伸長の影響を調べるために有用である(22).

そこで, 本研究では, 希薄混合気に高温窒素を対向 させた場合に希薄予混合気中に形成される維持火炎に おいて, その特性に及ぼす火炎伸長の影響について数 值計算により検討を行った.ここでは, 希薄混合気と 高温窒素の噴出速度を変えることにより, 火炎伸長率 を変化させた. そして, 各成分の反応速度や熱発生率, などを調べ，維持火炎の特性に及ぼす火炎伸長の影響 について検討を行った.

\section{- 2. 対向流予湿合火炎の数傗胡算方法}

希薄予混合気中の形成される維持火炎について検討 を行うために, 希薄可燃限界以下のプロパン一空気予 混合気と高温窒素とを組み合わせて, 図 1 に示すよう な対向流予混合火炎の計算を行った.

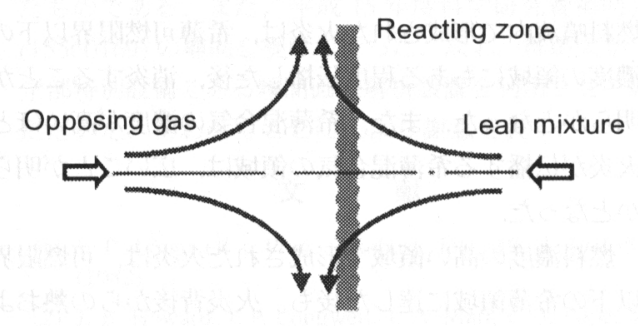

Fig. 1 Counterflow flames

Table 1 Calculation conditions

\begin{tabular}{|c|c|}
\hline \multicolumn{1}{|c|}{ Opposing gas } & Lean mixture \\
\hline $\mathrm{N}_{2}$ gas & Propane-air mixture \\
$T_{\mathrm{OP}}=1500,2000,2270$, & $\phi_{L}=0.13,0.27,0.40,0.47$, \\
$2500,2800 \mathrm{~K}$ & $0.54,0.67$ \\
& $T_{L}=293 \mathrm{~K}$ \\
\hline \multicolumn{2}{|c|}{$L=2 \mathrm{~cm}$} \\
$u_{0}=50,100,200,300 \mathrm{~cm} / \mathrm{s}$ \\
\hline
\end{tabular}

混合気組成を表 1 に示す，希薄混合気は，当量比ф

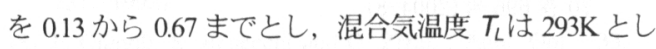
た.これに対向させた高温窒素の温度 $T_{\mathrm{OP}}$ は, 1500 か ら $2800 \mathrm{~K}$ までの範囲で変化させた。 このうち，T T $=2270 \mathrm{~K}$ は, 断熱平衡計算より求めた当量比 1.0 のプロ パンー空気予混合気の燃焼ガス温度である.

ガス噴出口間隔しは $2 \mathrm{~cm}$ とした. また, ふたつの噴 出口におけるガスの噴出速度は等しく $u_{0}$ とし， 50 ,

100,200 および $300 \mathrm{~cm} / \mathrm{s}$ とした.

火炎伸長率 $\alpha$ には, 火炎の予熱域前方における最大 の速度勾配を用いた(27)，このときの $\alpha$ の值は，中や $T_{\mathrm{OP}}$ により異なるが, ガスの密度を考慮せずに $2 u_{0} / L$ より見積もつた值の約 1.3 倍となった.

計算には, OPPDIF(28)コードと Law らのC3 までを 含む詳細反応機構(29)を用いた. 用いた反応機構の妥当 性を検証するために, PREMIX(28)コードによる一次元 平面火炎の計算を行った結果, 層流燃焼速度は, 従来 の測定結果 30 ) . (31) とほぼ一致することが確認されてい $ろ^{(16)}$.

\section{3. 対向流予混合火炎の数值計算結果およひ考察}

希薄混合気中に形成された維持火炎における各成分 の反応速度や熱発生率などに及ぼす火炎伸長の影響を 調べた.

$3 \cdot 1$ 然料の反応速度 まず，各素反応における プロパンの反応速度より, プロパンの反応速度 $\omega_{\mathrm{C} 3 \mathrm{H}}$ を求めた，つぎに，これらを対向流中心軸に沿つて希 薄混合気および対向ガスの両出口間で積分を行い,プ ロパンの反応速度の積分值 $\Sigma \omega_{\mathrm{C} 3 \mathrm{H}}$ を求めた. 本研究に おいては, 各成分の反応速度は生成される場合を正と するが, プロパンについてのみ，消費される場合を正 とした.

図 2 に, プロパンの反応速度の積分值 $\Sigma \omega_{\text {エ十⿱ }}$ の, 窒

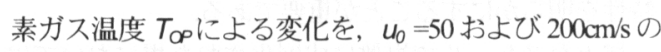
場合について示す.

図2 (a)の $u_{0}=50 \mathrm{~cm} / \mathrm{s}$ の場合, 希薄混合気の当量比ф が 0.13 から 0.54 の希薄可燃限界以下の濃度においては,

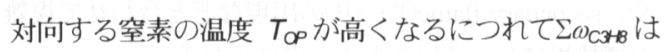
大きくなる. この炎は, 背後から高温窒素により維 持されているものと考えられる.

一方, 中=0.67においては, 混合気濃度が可燃範囲 内にあり(32), 自らで伝播可能な火炎(21)であるために, 対向する窒素の温度にほとんど依存しなかった：U0 $=100 \mathrm{~cm} / \mathrm{s}$ の場合も, これと同様の変化を示した.

しかしながら， $u_{0}=200$ および $300 \mathrm{~cm} / \mathrm{s}$ の場合には, $\phi_{L}=0.67$ においては, $T_{\text {oP }}=1500 \mathrm{~K}$ での $\omega_{\text {CB }}$ の值が小さ 
く, 図 2 (b)に示すように, $\phi$ L $=0.67$ における $\Sigma \omega_{C H B}$ の 厂 ○よる変化は, 当量比 $\phi$ が 0.13 から 0.54 までのも のと同様の変化となつた.

図3に, $u_{0}$ を変化させることにより得られた, 火炎 伸長率 $\alpha$ と $\omega_{C \text { CHB }}$ の関係を, $T_{\mathrm{OP}}=1500$ および $2270 \mathrm{~K} の$ 場合について示す.

図 3 (a)の $T_{\infty}=1500 \mathrm{~K}$ の場合, 当量比 $\phi_{L}=0.13$ から 0.54 においては, 火炎伸長率 $\alpha$ の增大とともに, プロパン の反応速度 $\Sigma \omega_{\text {Cか内 }}$ はすずかながら大きくなっている.

しかしながら， $\phi=0.67$ においては，火炎伸長率の 增大につれて小さくなつた. 特に $\alpha=130$ と $260 \mathrm{~s}^{-1}$ の間

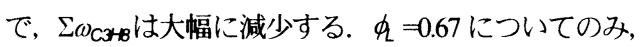
U に, $\alpha=185 \mathrm{~s}^{-1}$ 付近において, ステップ状に $\Sigma \omega_{\text {以 }}$ の值 が変化した.

ふたつの噴口より, ともに温度 $293 \mathrm{~K}$, 当量比 0.67 の混合気を噴出速度 $u_{0}=200 \mathrm{~cm} / \mathrm{s}$ で対向させた場合には, 火炎は伸長により消炎した. このときの $2 u_{0} /$ Lにより 見積もられる火炎伸長率は，200s ${ }^{-1}$ である．このことか ら, 可燃範囲内の燃料濃度である混合気においては, 火炎背後からの火炎維持効果を受けていない場合には,

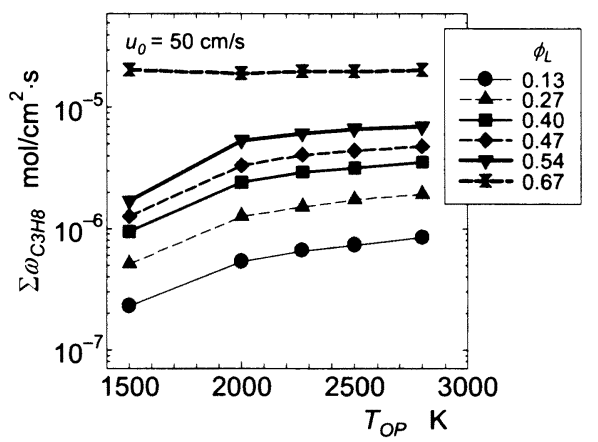

(a) $u_{0}=50 \mathrm{~cm} / \mathrm{s}$

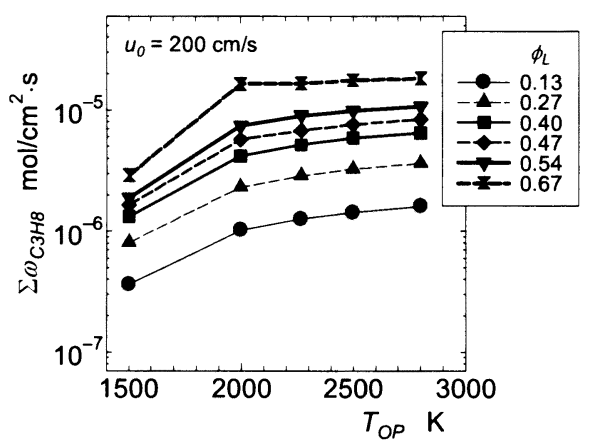

(b) $u_{b}=200 \mathrm{~cm} / \mathrm{s}$

Fig. 2 Variations of overall reaction rate of fuel, $\Sigma \omega_{\mathrm{C} 3 \mathrm{H}}$ with opposing gas temperature, $T_{O P}$
強い火炎伸長を受けると火炎は消炎するが, 高温窒素 による火炎維持効果を受けている場合には，消炎せず に維持火炎の形態に移行するものと考えられる.

$T_{\alpha p}=2000 \mathrm{~K}$ 以上の場合も, 当量比 $\phi_{L}=0.13$ から 0.54 に おいては, プロパンの反応速度 $\Sigma \omega_{G H}$ は $T_{O P}=1500 \mathrm{~K} の$ 場合と同様の変化を示した. しかしながら， おいては, $T_{\text {op }}=2000 \mathrm{~K}$ の場合には, $\alpha=130 \mathrm{~s}^{-1}$ 以上にお いても $\omega_{C \text { CB }}$ は急激に小さくなることはなかった. そ して, $T_{\text {oP }}=2270 \mathrm{~K}$ 以上では, 図3(b)に示すように, ф $=0.67$ の場合には, 火炎伸長率の増大につれて, 変化量 は小さいものの, $\Sigma \omega_{\text {CHB }}$ は一度小さくなつたのち大き くなっている.

混合気の噴出速度を大きくすると, 燃料の流量も増 す.プロパンの反応速度 $\Sigma \omega_{C \text { 瓜を }}$, 単位流量あたりの 值に換算し, $M_{\text {Car }} \Sigma \omega_{C H B} / Y_{\text {CaB }} \rho_{0} u_{0}$ として, $T_{\mathrm{OP}}=1500$ および 2270K の場合を図4に示す.ここで, $M_{\text {CHB }}$ は

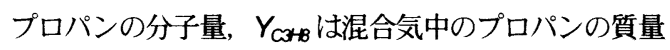
分率である.

どの温度においても, これらの場合と同様に, すべ ての当量比 ンの反応速度は単調に減少した.

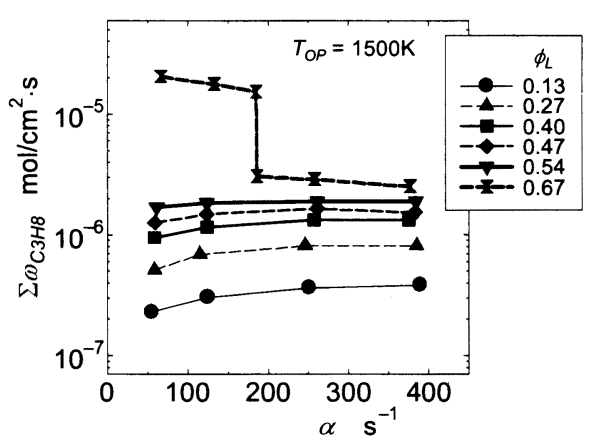

(a) $T_{\propto p}=1500 \mathrm{~K}$

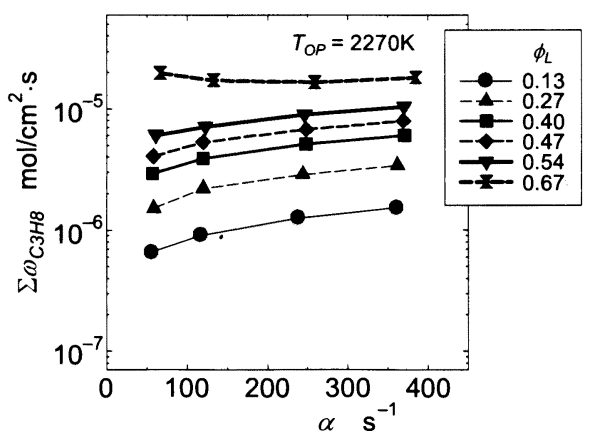

(b) $T_{\infty \circ}=2270 \mathrm{~K}$

Fig. 3 Variations of overall reaction rate of fuel, $\Sigma \omega_{\mathrm{C} 3 \mathrm{H} 8}$ with flame stretch rate, $\alpha$ 
以上より, 希薄混合気の当量比фが 0.13 から 0.54 の 希薄可燃限界以下の燃料濃度において, 高温の窒素か らの熱により維持されている火炎は，火炎伸長の影響 を受けていることが明らかとなった.

$\phi_{L}=0.67$ においては, 燃料濃度が可燃範囲内にある ことから, 火炎伸長率が小さい場合には, 対向するガ スの温度にも依存せず，火炎は自らで維持している. しかしながら，火炎伸長率が大きくなると維持火炎の 形態に移行し， $\phi=0.54$ 以下のときと同様に，対向する 窒素の温度および火炎伸長率への依存性を示すように なることが明らかとなった。

$T_{\infty p}=1500 \mathrm{~K}$ の場合に， $\phi_{L}=0.67$ において自らで伝播可 能であった火炎が，火炎伸長により維持火炎の形態に 移行すると, 火炎の位置にもその変化が認められた.

ここでは, プロパンの反応速度 $\omega_{C \text { СH }}$ が最大となる 位置を火炎の位置とし, よどみ点から火炎までの距離 を図 5 に示す。炏は，符号が正の場合によどみ点よ りも希薄混合気側にあり, 負の場合は高温空素側に位 置する.

図 5 (a)に示す $T_{\alpha p}=1500 \mathrm{~K}$ の場合には, 希薄混合気の 当量比多が 0.13 から 0.54 においては, 全ての火炎伸長

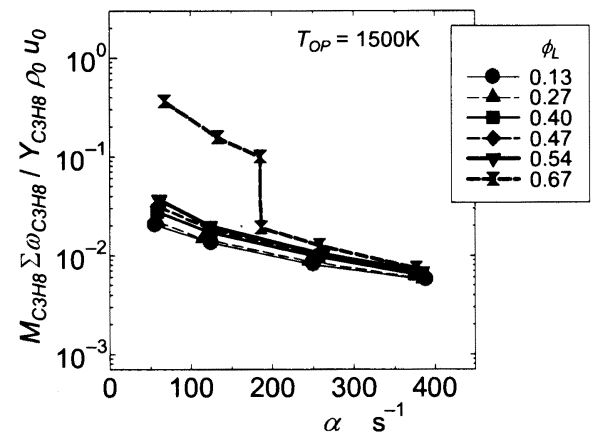

(a) $T_{\alpha p}=1500 \mathrm{~K}$

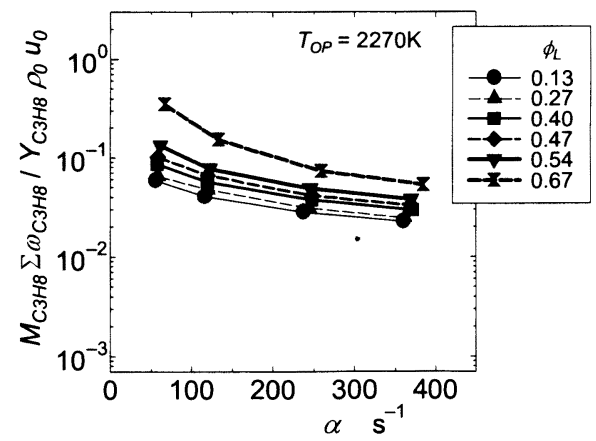

(b) $T_{O P}=2270 \mathrm{~K}$

Fig. 4 Variations of normalized overall reaction rate of fuel, $M_{C H B} \Sigma \omega_{C H B} / Y_{C H B} \rho_{0} u_{0}$ with flame stretch rate, $\alpha$
率 $\alpha$ において，火炎はよどみ点よりも後方，つまり対 向する高温空素側にある。

$\phi_{L}=0.67$ の場合には, 火炎伸長率 $\alpha$ 小さいときは, 火炎は希薄混合気側にあるが, $\Sigma \omega_{\text {Caー }}$ の値がステップ 状に変化する $\alpha=185 \mathrm{~s}^{-1}$ 以上では, 当量比中が 0.54 以下 の場合と同様に，火炎の位置が対向する空素側に移動 する.

また，これらの炎は，図5(b)のように，対向空素 の温度が高い場合には，希薄混合気上流側に位置する。 維持火炎は，対向する窒素の温度に依存している(16).

このことからも, 可燃範囲内のф $=0.67$ においても, 強い火炎伸長を受けることにより，維持火炎の形態に 移行しているものと考えられる。

また，このような，よどみ点よりも後方に位置する 火炎は, 自ら維持, 伝播する火炎ではないものの, 負 の燃焼速度(3)(19)をもつことになる.

$3 \cdot 2$ 淮持火炎での反応およひ勄発生率 つぎ に，これら高温空素に維持された火炎での反応の特性 を検討するために，一酸化炭素の反応速度について調 べた. Takeno と Nishioka( $\left.{ }^{33}\right)$ による El(Emission Index) と同 様に, $\mathrm{CO}$ の反応速度の積分值 $\Sigma \omega_{\mathrm{CO}}$ とプロパンの反応

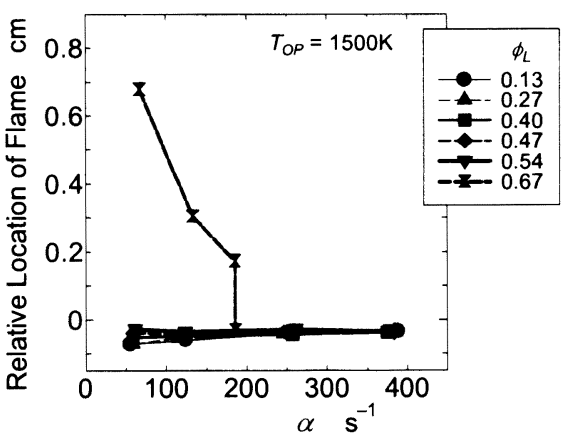

(a) $T_{\mathrm{OP}}=1500 \mathrm{~K}$

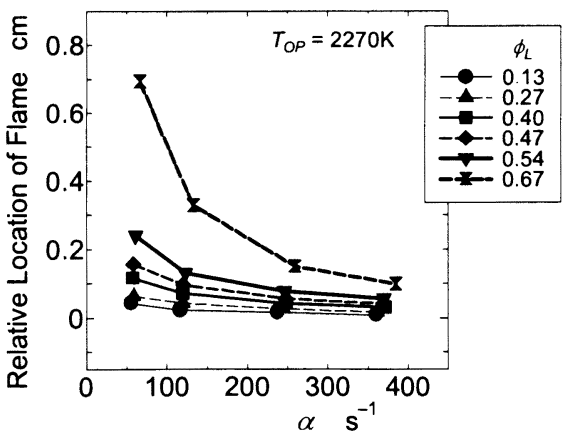

(b) $T_{\infty}=2270 \mathrm{~K}$

Fig. 5 Relative locations of flame from stagnation point 


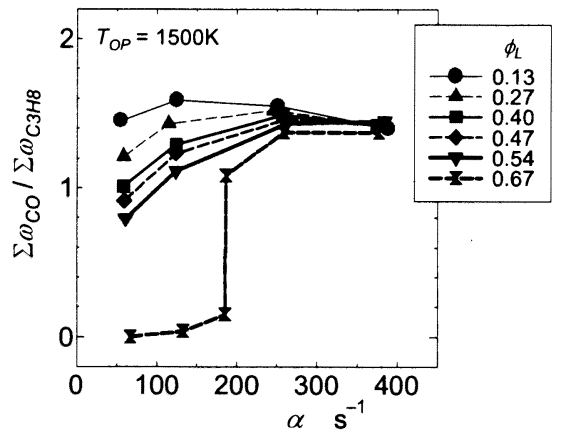

(a) $T_{O p}=1500 \mathrm{~K}$

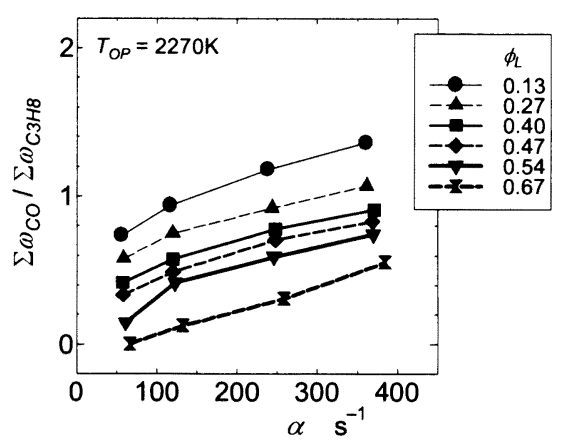

(b) $T_{\alpha p}=2270 \mathrm{~K}$

Fig. 6 Ratios of overall reaction rate of $\mathrm{CO}$ to fuel, $\Sigma \omega_{C \mathrm{O}} / \Sigma \omega_{\mathrm{C} \text { нH }}$

速度の積分値 $\Sigma \omega_{\text {Ca日 }}$ との比を求めた.

図6(a)および(b)に，それぞれ $T_{o p}=1500$ および2270K の場合を示す. 対向する窒素の温度 $T_{\alpha p}$ が $2000 \mathrm{~K}$ 以上 の場合には, 図6(b)に示すように, 火炎伸長率の増大 につれて, どの当量比れにおいても $\Sigma \omega_{C O} / \Sigma \omega_{\text {CaHB }}$ の值 は大きくなっている.ここには示していないが, $\mathrm{CO}_{2}$ については, $\Sigma \omega_{\mathrm{CO} 2_{2}} / \Sigma \omega_{\mathrm{CH}}$ の值は小さくなった.

これらより, 火炎伸長率の増大につれて, プロパン の酸化反応が完全に行われずに，燃料の消費量に対す る一酸化炭素の生成される割合が大きくなつたものと 考えられる. Yamaoka と Tsuji 21 は, 可燃限界以下の 火炎においては, 燃焼反応が完結しないとしている.

一方, 図6 (a)に示す $T_{\alpha p}=1500 \mathrm{~K}$ の場合には, 希薄混 合気の当量比台が 0.13 から 0.47 の場合, $\Sigma \omega_{C O} / \Sigma \omega_{\text {CrB }}$ の值は, 火炎伸長率の増大につれて一度增加するもの の, その後やや減少している. これは, 対向する窒素 の温度が低く火炎維持効果が小さいために, 火炎伸長 の影響を大きく受け, プロパンが一酸化炭素にまでも 酸化されないためと考えられる.これらの場合, $\left(\Sigma \omega_{C O R}+\Sigma \omega_{C O}\right) \Sigma \omega_{C F H}$ の值は, プロパンの化学量論式

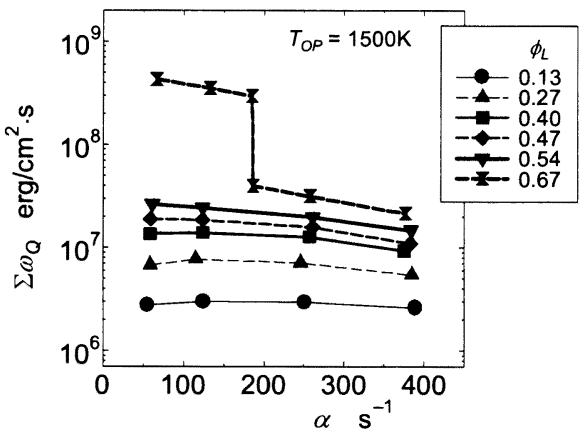

(a) $T_{\mathrm{Op}}=1500 \mathrm{~K}$

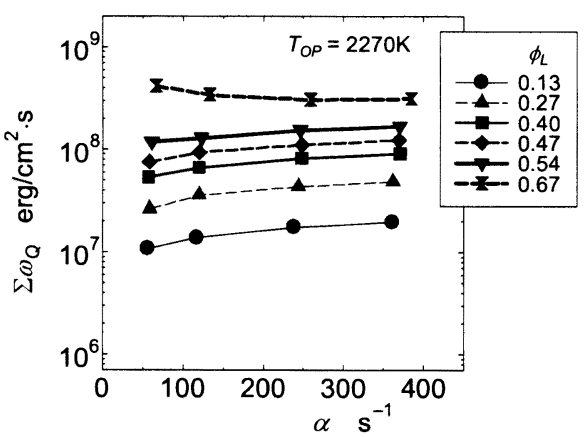

(b) $T_{\text {op }}=2270 \mathrm{~K}$

Fig. 7 Variations of overall heat release rate, $\Sigma \omega_{Q}$ with flame stretch rate, $\alpha$

におけるプロパンと二酸化炭素の分子数の比である 3 よりかなり小さく, 2 程度である.

このような場合には, エチレンなどの未燃炭化水素 成分が多く残されていた.

対向流中心軸に沿っての両出口間での熱発生率の積 分値 $\Sigma \omega_{\mathrm{Q}}$ を, 図 7 に示す. $T_{\alpha p}=1500 \mathrm{~K}$ の場合, プロパ ンの反応速度 $\Sigma \omega_{G \text { B }}$ は, 図 3 (a)に示すように当量比中 $=0.13$ から 0.54 においては, 火炎伸長率 $\alpha$ の増大ととも にわずかながら大きくなっている. しかしながら，熱 発生率 $\Sigma \omega_{Q}$ は, 図7 (a)に示されるように, 火炎伸長率 $\alpha$ の增大につれて, わずかながらではあるが滅少して いる.

反応により消費されるプロパンの量は, 混合気流量 の増加につれて増すものの, 火炎伸長の増大により完 全には酸化されないために, 熱発生率が減少している ものと考えられる. このことからも， $T_{o p}=1500 \mathrm{~K}$ の場 合には燃焼反応が完結していないことがわかる. $T_{\text {op }}$

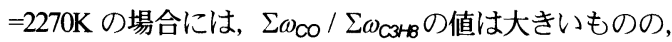
熱発生率 $\Sigma \omega_{Q}$ は, 図 7 (b)に示されるように, 火炎伸長 率 $\alpha$ に対して図 3 (b)の $\omega \omega_{\text {CHB }}$ と同様に変化した. 


\section{4.}

成層混合気中を希薄領域へ伝播する火炎を，火炎お よびその背後の燃焼ガスと前方にある希薄混合気の相 互作用としてとらえ，可燃限界以下の希薄予混合気に 高温窒素を対向させる対向流予混合火炎の数値計算を 行い, 成層混合気における希薄領域へ伝播する火炎の 特性に及ぼす火炎伸長の影響を調べた.

その結果, 希薄可燃限界以下の濃度の混合気におい て，背後から高温窒素により維持されている火炎は, 火炎伸長の影響を受けていることが明らかとなった. 火炎伸長率の増大とともに，プロパンの反応速度はわ ずかながら大きくなっている. しかしながら，その増 加割合は混合気流量の増加割合より小さく, 混合気単 位流量あたりの反応速度は，火炎伸長により低下して いる.

また，可燃範囲内の濃度の混合気における火炎につ いては，火炎維持効果が無い場合には消炎するような 強い火炎伸長を受けると, 維持火炎の形態に移行し, 可燃限界以下の維持火炎と同様な火炎伸長率への依存 性を示すことが明らかとなった.

さらに，火炎伸長が強いときには，燃焼反応が完結 せず，一酸化炭素や未燃炭化水素の生成割合が増大す る.

\section{文部}

(1) Abata, D. and Evans, RL, Automotive Engine Altematives, Plenum Publishing Corporation, New York, 1987.

(2) Takagi Y, A New Era in Spark-Ignition Engines Featuning High-Pressure Direct Injection, Proc. Combustion Institute, 27, (1998), 2055-2068.

(3) Sohrab, S.H., Ye, ZY. and Law, CK, An Experimental Investigation on Flame Interaction and the Existence of Negative Flame speeds Proc. Combustion Institute, 20, (1984), 1957-1965.

(4) Tanoff, M, Smooke, MD, Osborme, RJ, Brown, T.M. and Pitz RW, The Sensitive Structure of Partially Premixed Methane-Air vs. Air Counterflow Flames, Proc. Combustion Institute, 26, (1996), 1121-1128.

(5) Lockett, RD., Boulanger, B., Harding, S.C. and Greenhalgh, D.A., The Structure and Stability of the Laminar Counter-flow Partially Premixed Methane/Air TripleFlame, Combustion and Flame, 119, (1999), 109-120.

(6) Daou, J., Matalon, M. and Liñán A., Premixed Edge-Flames under Transverse Enthalpy Gradents", Combustion and Flame, 121, (2000), 107 121.

(7) Dold, J.W, Flame Propagation in a Nonunifrom Mixture: Analysis of a Slowly Varying Triple Flame, Combustion and Flame, 76, (1989),71-88.

(8) Librovich, B.V., Makhviladze, GH., Roberts, JP. and Yakush, S.E., Numerical Analysis of Laminar Combustion of Fuel Gas Clouds Combustion and Flame, 118,(1999), 669-683.

(9) Kĩoni, PN, Bray, KN.C., Greenhalgh, D.A. and Rogg B., Experimental and Numerical Studies of a Triple Flame, Combustion and Flame, 116, (1999), $192-206$
(10) Peters, N., Turbulent Combustion, Cambridge University Press, Cambridge, 2000.

(11) Haworth, D.C, Blint, RJ, Cuenot, B. and Poinsot, TJ., Numeical Simulation of Turbulent Propane-Air Combustion with Nonhomogeneous Reactarts, CombustionandFlame, 121,(2000), 395417.

(12) Kitagawa, T, Kido, H., Kim, K.S., Deguchi, T. and Yamashita, J., Combustion of Stratified Mixture Formed by Gas Fuel Jet, Proc. 5th International Symposium on Diagnostics and Modeling of Combustion in Intermal Combustion Engines, (2001), 258-264.

(13) 北川, 城戸, 出口, 山下, 気体燃料噴流による成層混合気の燃焼 特性, 日本機械学会論文集, 67-658,B (2001), 1549-1554.

(14) 北川, 気体然料噴流により形成された成層混合気の燃焼特性, エンジンテクノロジー,Vol. 4,No. 2,(2002), 3845.

(15) 北川, 城戸, 金, 藤岡, 気体燃料噴流により形成された成層混合 気中における希薄領域への火炎伝播特性, 日本機械学会論文 集,, 68-673, B (2002),2657-2663.

(16) 北川, 城戸, 金, 藤岡, 成層混合気中を希薄領域へ伝播する火炎 の対向流火炎による検討, 日本機珹学会諭文集, 69-682, B (2003), 1515-1520.

(17) Marzouk, YM., Ghoniem, AF. and Najm, HN, Dynamic Response of Stratified Premixed Flames to Equivalence Ratio Gradients, Proc. Combustion Institute, 28, (2000), 1859-1866.

(18) Ra, Y. and Cheng, WK, Laminar Flame Propagation through a StepStratified Charge, Proc. 5th Intemational Symposium on Diagnostics and Modeling of Combustion in Intemal Combustion Engines (2001), 251-257.

(19) Wehrmeyer, J.A, Chen Z, Mosbacher, M., Pit, RW. and Osborne, R. Opposed Jet Flames or Rich Premixed Propane-Air Reactants versus Hot Products, Combustion and Flame, 128, (2002), 232-241.

(20) 田上, 江原, 北川, 不均質瀑度場における対向流火炎の NO生成 に関する数値計算,自動車技術会論文集, 334,(2002),51-56.

(21) Yamaoka, I. and Tsuij, H, An Experimetal Sudy of Flammability Limit Using Counterflow Flames, Proc. Combustion Institute, 17, (1979), 843-855.

(22) 大塚, 新岡, 対向二次元流バーナにおける定常 次元拡散炎, 日 本機械学会論文集, 38-310,(1972), 1513-1522.

(23) Sato, J, Konishi, K, Okada, H. and Niioka, T, Ignition Process of Fuel Spray Injected int High Pressure High Temperature Atmosphere, Proc. Combustion Institute, 21: 695-702 (1986)

(24) 北野,大塚,対向流における自発火の研究,日本機戍学会論文集, 45-400, B (1979), 1902-1911.

(25) 北川, 城戸,戸上, 原田, 小川, 層流燃焼速度および Markstein 長さ に及ぼす圧力の影響, 第 17 回内燃機関シンボジウム講演論文 集,(2002),309-314.

(26) 北川, DBradley, C.G.W.Sheppard, R.Woolly, 高圧下における予混合 気の乱流然焼特性, 日本機珹学会徳島地方講演会講演諭文集, (2000), 243-244.

(27) Fotache, C.G., Wang H. and Law, C.K., Ignition of Ethane, Propane, and Butane in Counterflow Jets of Cold Fuel versus Hot Air under Variable Pressures, Combustion and Flame, 117,(1999), 777-794.

(28) Kee, RJ., Rupley, F.M., Mille, J.A, Coltrin, ME, at al., CHEMKIN Collection, Release 3.6, Reaction Design, Inc, San Diego, CA (2000).

(29) Sung, CJ., Li, B, Law, C.K. and Wang, H., Structure and Sooting Limits in Counterflow Methane/Air and Propane/Air Diffision Flames from 1 to 5 Atmospheres. Proc. Combustion Institute, 27, (1998), 1523-1529.

(30) Yamaoka, L and Tsuji, H., Determination of Buming Velocity Using Counterflow Flames, Proc. Combustion Institute, 20, (1984), 1883-1892.

(31) Egolfopoulos, FN, Zhu, DL. and Law, CK, Experimertal and Numerical Determination of Laminar Flame Speeds: Mixtures of $\mathrm{C}_{2}$-Hydrocarbons with Oxygen and Nitrogen. Proc. Combustion Institute, 23,(1990), 471 478.

(32) Lewis, B. and von Elbe, G., Combustion, Flames and Explosions of Gases (3rd ed), Academic Press Inc, Orlando, 1987, p. 706.

(33) Takeno, T. and Nishioka, M.: Species Conservation and Emission Indices for Flames Described by Similarity Solutions, Combustion and Flame, 92, (1993), 465468 . 